\title{
PENERAPAN METODE TIPOLOGI WATER ARCHITECTURE DALAM RUANG EDUKASI DAN REKREASI PENGOLAHAN AIR JAKARTA
}

\author{
Chavia $^{1}$ \\ ${ }^{1}$ Program Studi S1 Arsitektur, Fakultas Teknik, Universitas Tarumanagara, veronikachavia@yahoo.com
}

\begin{abstract}
Abstrak
Air dan sanitasi adalah prioritas utama bagi kehidupan Kota Jakarta namun keadaan wadah air yang ada di Kota Jakarta tidak terawat. Milenial memiliki peran yang signifikan terhadap masalah lingkungan dan isu alam karena generasi milenial merupakan agen perubahan vital yang akan menentukan bagaimana nantinya keadaan lingkungan sekitarnya. Ruang edukasi dan rekreasi pengolahan air Jakarta adalah sebuah wadah interaksi bagi generasi milenial dan warga Kota Jakarta yang ditambahkan nilai edukasi tentang air. Proyek ini didesain dengan sebagai ikon ekologis urban Jakarta dengan misi menjadi fasilitas edu- eko turisme yang terbuka untuk melibatkan dan menginspirasi masyarakat untuk peduli untuk air. Metode studi tipologi ekspresi bentuk bangunan dan program bangunan pengolahan air limbah yang sudah ada di negara maju merupakan salah satu metode yang digunakan dalam merancang pemograman arsitektur. Metode tipologi, air dan arsitektur dengan kaitannya menamilkan ekpresi arsitektur berbasis air yang ikonik adanya konsep rekreatif pengolahan air di limbah diwujudkan dengan memberikan upaya penggabungan desain dengan pengolahan air limbah (PAL) di Waduk Setiabudi dengan menggunakan jembatan sehingga pengunjung mendapatkan edukasi dengan melihat langsung sistem pengolahan air limbah Waduk Setiabudi.
\end{abstract}

Kata kunci: fasilitas edu-eko turisme; pengolahan air limbah; rekreatif edukatif

\begin{abstract}
Water and sanitation are the top priorities for the city of Jakarta, however, the air containers in Jakarta are not maintained. Millennial has a significant role in environmental and natural issues because the millennial generation is a vital change agent that will determine how to deal with the surrounding environment. The Jakarta water treatment and recreation room is a place of interaction for millennials and residents of Jakarta City that adds value to education about air. This project was designed with the ecological icon of urban Jakarta with the mission of being an educational educational facility that is open to facilitate and inspire people for air interests. The typology study method reveals the shape of buildings and waste water treatment building programs that already exist in developed countries is one of the methods used in the completion of architectural programming. Approved by typology, air and architecture methods, the expression of the iconic water-based architecture from the recreational concept of wastewater treatment was created by providing support for the design of wastewater treatment (PAL) in the Setiabudi Reservoir using bridges that are looking for education by looking directly at the treatment system Setiabudi Reservoir wastewater.
\end{abstract}

Keywords: edu-eco tourism facilitie; educational recreation; waste water treatment 


\section{PENDAHULUAN}

Kota Jakarta sebagai ibukota memiliki karakter sebagai kota metropolitan yang sangat kuat namun dibeberapa wilayah Kota Jakarta masih memiliki banyak masalah. Salah satu masalah yang dimiliki Kota Jakarta adalah sebagian besar penduduk Kota Jakarta sering membuang sampah mereka ke sungai atau ke waduk sehingga menjadi tercemar sedangkan air adalah sumber kehidupan manusia. Air, sanitasi, dan higienis adalah prioritas utama di Jakarta untuk kebutuhan kota. Jakarta memiliki potensi besar untuk meningkatkan penggunaan sumber daya airnya. Hal itulah yang kurang disadari oleh kebanyakan warga Jakarta, reservoir tempat penampungan air sementara di Kota Jakarta yang diharapkan dapat membantu menampung air saat musim hujan di penuhi dengan sampah dan tidak terawat menurut artikel Pal Jaya sehingga masalah banjir tidak terselesaikan. Masalah lingkungan ini akan terselesaikan jika setiap manusia dalam kota dapat mengambil perannya masing-masing untuk melakukan perubahan, khususnya generasi milenial, generasi millennial memiliki peran yang signifikan terhadap masalah lingkungan dan isu alam karena generasi millennial merupakan Agen perubahan yang vital yang akan menentukan bagaimana nantinya keadaan lingkungan sekitarnya. Dengan program yang di usulkan diharapkan akan menjadi ruang rekreasi bagi generasi milenial dan warga kota Jakarta untuk bersenang senang dan berinteraksi dengan nilai lebih, yaitu dengan edukasi mengenai pentingnya pengolahan air.

\section{KAJIAN LITERATUR}

\section{Genarasi Milenial}

Milenial adalah kelompok demografi Generasi Y. Para ahli dan peneliti biasanya menggunakan awal 1980-an sebagai awal kelahiran kelompok ini dan pertengahan tahun 1990-an hingga awal 2000-an sebagai akhir kelahiran. Menurut Teori William Strauss dan Neil Howe (1991), generasi Y banyak menggunakan teknologi komunikasi instan seperti email, sms, instant messaging dan media sosial.

Generasi ini merupakan generasi yang mendominasi dunia kerja di Indonesia maupun di mancanegara saat ini menurut Harari Y.H (2015) Generasi Y adalah generasi yang menerapkan kreativitas serta berfokus pada pengembangan diri sehingga cenderung memilih pekerjaan yang menyenangkan bagi mereka dan cenderung berhura-hura. Berikut ini merupakan kesimpulan ketika sifat dasar manusia beserta struktur sosial disilangkan dengan mileial akan menimbulkan suatu ruang yang hilang karena terganti dengan yang baru atau bertahan.

\section{Pengertian Arsitektur yang Rekreatif dan Edukatif}

Arsitektur memiliki pengertian sebagai ilmu yang mempelajari tentang lingkungan binaan, yang diperuntukkan bagi manusia sebagai penggunanya Deviyana (2016). Rekreatif merupakan kata sifat yang berasal dari kata dasar rekreasi yang bersifat dapat mengekspresikan dan menjelaskan aktifitas yang dilakukan pada waktu senggang. Hal ini dapat dilakukan untuk membentuk, meningkatkan kembali kesegaran fisik, mental, pikiran dan daya kreasi yang hilang akibat rutinitas sehari-hari dengan jalan mencari kesenangan, hiburan dan kesibukan yang berbeda yang dapat memberikan kepuasan dan kegembiraan yang akhirnya ditujukan bagi kepuasan lahir dan batin. Edukatif merupakan kata sifat yang berasal dari kata dasar edukasi yang memiliki arti bersifat mendidik. Dengan kata lain kegiatan yang memberikan kegiatan yang mencerdaskan dan menambah wawasan pengetahuan. Jadi, dapat disimpulkan bahwa arsitektur rekreatif edukatif adalah konsep merancang suatu bangunan yang bersifat memberi penyegaran kembali baik jasmani dan rohani seseorang, sekaligus dapat memberikan pembelajaran dan pemahaman yang mencerdaskan dan menambah wawasan pengetahuan.

\section{Faktor yang Diperlukan Dalam Arsitektur Rekreatif Edukatif}

Dilihat dari jenis dan ciri maka berikut faktor yang diperlukan dalam arsitektur rekreatif edukatif yaitu faktor lokasi sebagai medium untuk menciptakan area rekreatif ditambah 
dengan suntikan program dalam menciptakan area edukasi lalu faktor arsitektur sebagai pendukung dalam menciptakan pengalaman ruang yang rekreatif dan edukatif.

\section{Ciri dari Rekreatif Edukatif}

Adapun ciri dari rekreatif edukatif Deviyana (2016). adalah kegiatan yang terjadi di dalamnya dapat memberi penyegaran dan kegembiraan bagi pengunjung.

- Kegiatan mendidik, mempelajari, dan mengetahui sesuatu melalui aktifitas yang menyenangkan dan bersifat menghibur.

- Kegiatan yang memberikan kegembiraan dan pengetahuan kepada pelaku dalam waktu yang bersamaan.

\section{Jenis - Jenis Kegiatan Rekreatif Edukatif}

Jenis- jenis kegiatan yang bersifat edukatif - rekreatif diantaranya: Deviyana (2016).

- Big muscle activities: rekreasi yang memerlukan tenaga atau fisik.

- Social activities: rekreasi yang bertujuan sosial, seperti: bercakap-cakap, jalan-jalan bersama, melibatkan interaksi sosial sebagi kegiatan utama.

- Physical recreation: memerlukan usaha atau kegiatan fisik sebagai kegiatan utama.

- Cognitive recreation: melibatkan kebudayaan, pendidikan, dan kreatifitas.

- Environment -related recreation: rekreasi yang memanfaatkan potensi alam dalam kegiatannya, seperti olahraga arung jeram.

- Rhythms and music: rekreasi yang diakibatkan oleh irama dan musik yang memberikan kesenangan, persahabatan, seperti bernyanyi dan berdansa.

- Hand intellect: rekreasi yang mengembangkan keterampilan tangan dan pikiran, misalnya: melukis dan mematung.

- Nature learning: rekreasi di alam terbuka (berkemah dan mendaki gunung).

- Mental: rekreasi yang merupakan ekspresi dari aktifitas masyarakat yang berisfat mendidik, misalnya: berdebat, berdiskusi, dan lain-lain.

- Relaxation: rekreasi yang bertujuan melepaskan diri dari ketegangan dan kelelahan mental dan fisik untuk mencapai kesenangan dan kesegaran, misalnya; menikmati pemandangan alam, duduk di taman, dan lain-lain.

\section{Ruang Terbuka Hijau Sebagai Ruang Publik}

Ruang terbuka (Open Space) merupakan ruang yang di rencanakan karena kebutuhan akan tempat- tempat pertemuan dan aktivitas bersama di ruang terbuka. Ruang Terbuka (Open Space), Ruang Terbuka Hijau (RTH), Ruang Publik (Public Space) mempunyai pengertian yang hampir sama. Ruang terbuka hijau adalah suatu wadah yang menampung aktivitas manusia dalam suatu lingkungan yang tidak mempunyai penutup berbentuk fisik.

\section{Studi Tipologi Program Water Architecture}

Dalam perancangan ruang edukasi dan rekreasi pengolahan air Jakarta preseden yang digunakan merupakan bangunan air yang ikonik yang sudah ada di negara maju dan dianalisis programnya. Dari hasil analisis yang dilakukan bangunan dengan fungsi program pengolahan air di negara maju sudah sangat diperhatikan dan tidak hanya memiliki satu fungsi yaitu sebagai pengolahan air saja melainkan dimasukan beberapa program lain yang menarik seperti pusat perbelanjaan - mall, edukasi, retail dan restaurant. Bangunan juga mengundang warganya ataupun wisatawan karena banngunan juga merupakan bangunan publik.

\section{METODE}

Metode analisis dilakukan dengan mengolah data domisili milenial di Kota Jakarta sebagai acuan penentu kawasan dan analisis. Setelah itu dilanjutkan analisis makro untuk melihat kriteria lokasi dengan aktivitas pengolahan air dan hiburan yang tinggi. Sudirman merupakan tempat dengan tingkat prduktivitas dan aktivitas yang tinggi dalam rekreasi dan edukasi. 


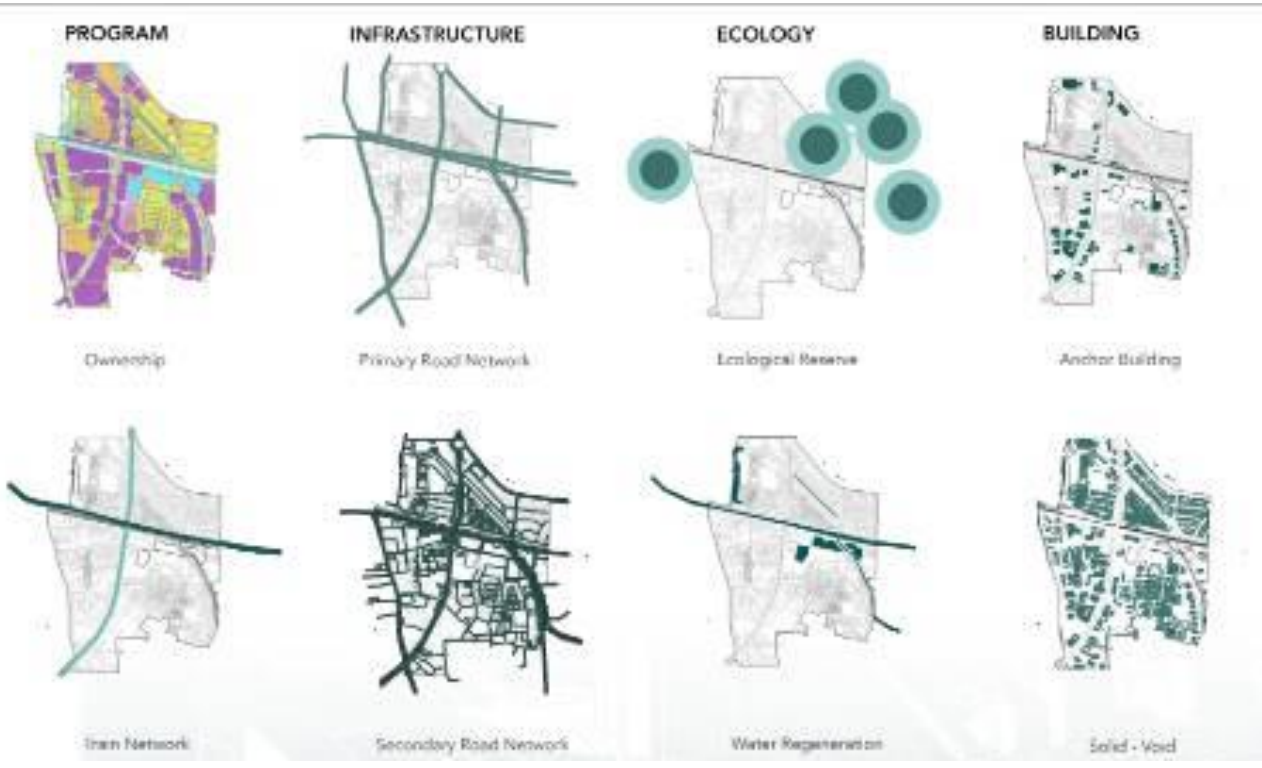

Gambar 1. Makro Analisis

Sumber: Penulis, 2019

Dalam tahap desain digunakan beberapa metode desain sebagai berikut:

\section{Metode Tipe-Perilaku Milenial Dalam Perancangan}

Dalam perancangan proyek Ruang Edukasi dan Rekreasi pengolahan air Jakarta dilakukan enganalisis tipe dan perilaku milenial dilakukan berdasarkan data riset generasi millennial di Jakarta, dan juga warga kota Jakarta yang mulai peduli akan lingkungan dan dapat menjadi agen perubahan yang dapat membawa perubahan baru kepada generassi mendatang. Mereka juga suka melakukan kegiatan berinteraksi satu sama lain dan lebih senang menghabiskan waktu bersama. Melihat potensi yang ada maka desain program ini berkonsep menciptakan suatu ruang interaksi baru di kota Jakarta dan di tambahkan nilai yang lebih yaitu mengedukasi warga kotanya tentang isu lingkungan dan peran air yang ada di dalam kota Jakarta, agar warga Kota Jakarta mendapatkan edukasi tentang air sehinggamengerti bahawa air adalah sumber kehidupan bagi manusia dan merupakan salah satu struktur pembentuk kota yang sangat penting.

\section{Metode Tipologi Perancangan Water Architecture}

Berikut adalah gambar pembahasan metode tipologi perancangan arsitektur dan air:
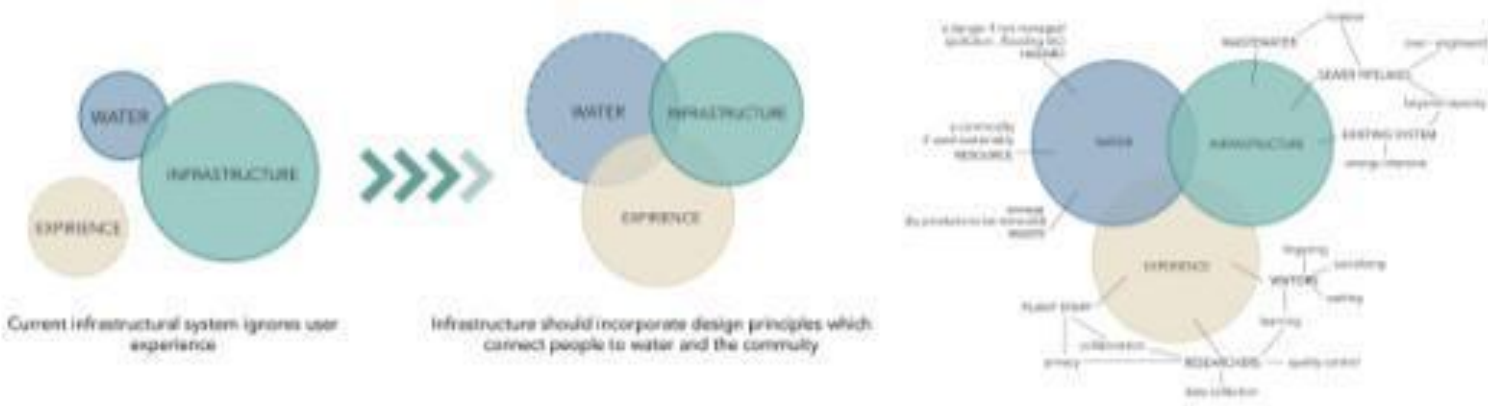

Gambar 2.Diagram Metode Tipologi

Sumber : Penulis, 2019 
Dalam perancangan ruang edukasi dan rekreasi pengolahan air Jakarta menggunakan metode tipologi arsitektur dan air yang mengambil makna dari elemen air dan menggabungkannya dengan pengalaman ruang baru untuk menjadi suatu desain bangunan. Metode yang di gunakan akan menggabungkan infrastruktur air yang sebelumnya bersifat tertutup dengan program edukasi yang terbuka kepada publik sehingga menjadi ruang edukasi dan rekreasi pengolahan air Jakarta.

\section{Metode Arsitektur dan Air Sebagai Transformasi Perancangan}

Kehadiran air yang di bawa ketengah pusat kota akan memunculkan sentralisasi karena posisinya yang terletak di pusat inti. Sentralitas tidak hanya dimasukkan ke dalam arsitektur dan urbanisme. Dalam perancangan di terapkan juga di dalam:

- Forming, formable

- Inviting, bonding, separator

- Landscape dan visual

- Water As A Show

Elemen air akan memberikan mode yang berbeda dan kontras terhadap bangunan di sekitarnya sehingga menciptakan lanskap khusus untuk mencerminkan wajah kota yang ekologi.

\section{DISKUSI DAN HASIL}

Ruang edukasi dan rekreasi pengolahan air Jakarta dirancang dengan beberapa strategi desain yang memperhatikan Tipe dan perilaku pengunjung khususnya perilaku generasi milenial yang merupakan agen perubahan (Agent of change) sebagai sasaran utama program ini. Strategi Desain dalam Ruang edukasi dan rekreasi pengolahan air Jakarta ini juga menggunakan metode tipologi yang berdasarkan preseden bangunan pengolahan air yang ada di Negara maju dan menganalisis bagaimana programnya di input kedalam bangunan.

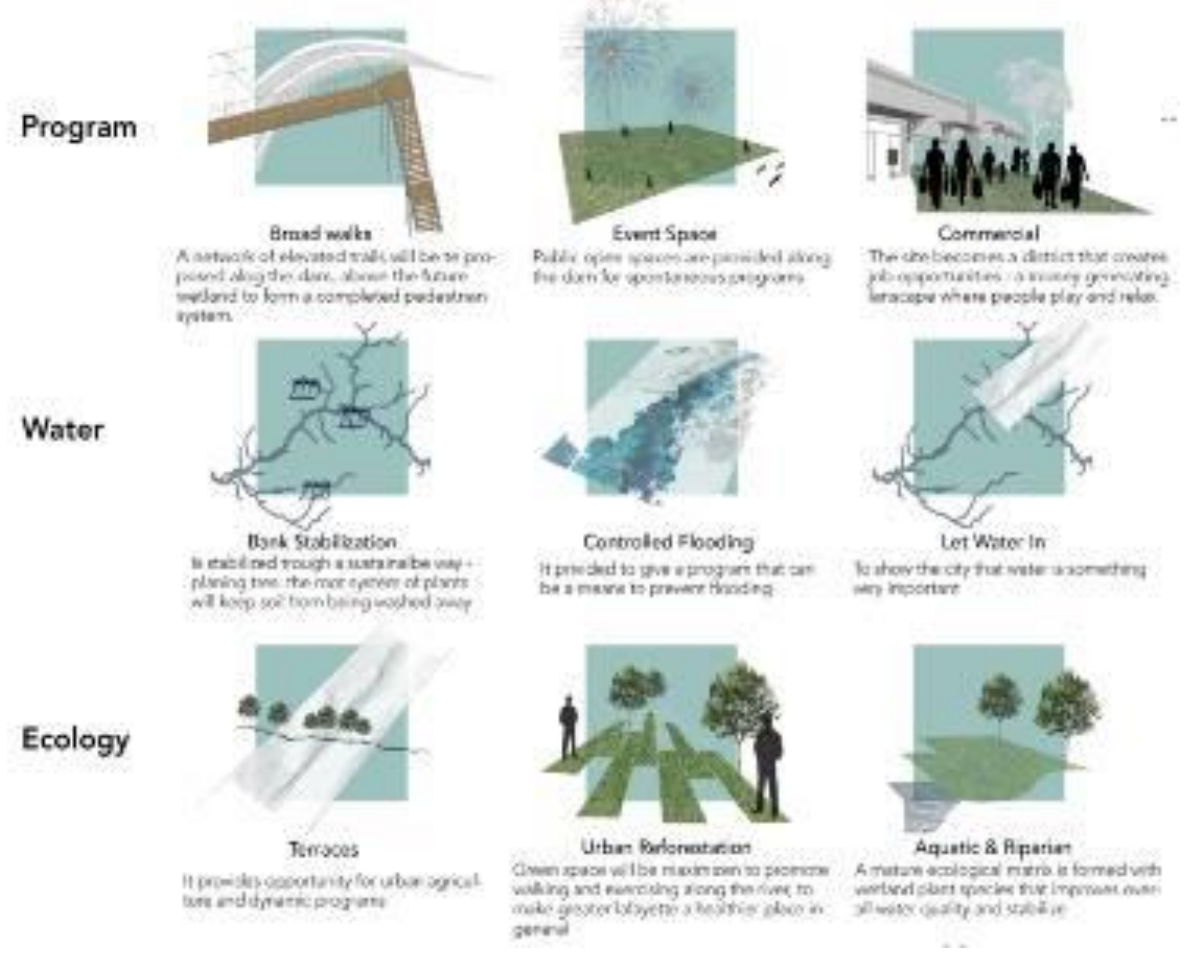

Gambar 3. Diagram Besaran Program

Sumber: Penulis, 2019 
Ruang edukasi dan rekreasi pengolahan air Jakarta yang berlokasi di Setiabudi, Jakarta Selatan berada di lingkungan kawasan yang memiliki tingkat prduktivitas dan aktivitas yang tinggi dalam rekreasi dan edukasi dan berbatasan langsung dengan J. Jendral Sudirman. Proyek dengan luas tapak $\pm 12.250 \mathrm{~m}^{2}$ memiliki program utama berupa menara observasi $(45 \%)$, program kedua berupa galeri $(35 \%)$, program pendukung retail $(10 \%)$, dan servis (10\%).

Aktivitas utama dalam bangunan ruang edukasi dan rekreasi pengolahan air Jakarta ini menggabungkan edukasi tentang air dengan pengolahan air limbah (wastewater). Berikut adalah diagram analis aktivitas yang di lakukan dalam perancangan.

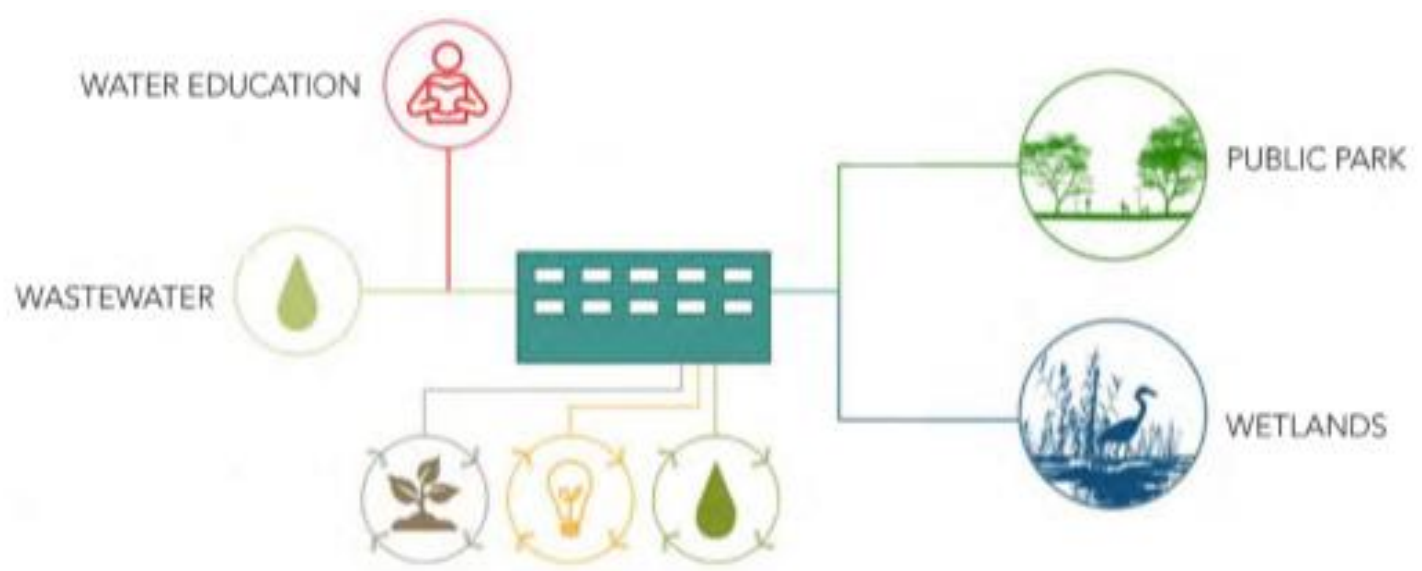

Gambar 4. Diagram Analisis Aktivitas

Sumber: Penulis, 2019

Aktivitas galeri dalam bangunan yang berada di lantai dasar berisikan edukasi tentang air untuk menyadarkan pengunjungnya tentang pentingnya air dan menara observasi yang membawa ke pengalaman ruang untuk mendapatkan kesadaran tengan apa arti air bagi kehidupan kota. Kedua aktivitas tersebut di satukan dengan detambahkan unsur taman publik dan lahan basah / wetland di tengah bangunan sebagai area communal dan titik interaksi yang ada di dalam bangunan.

Dengan pendekatan dari teori dan metode yang digunakan berdasarkan tipologi dan bentuk bangunan bangunan yang mengutamakan elemenn air dan banngunan yang berada di sekitar air bebentuk bulat dan bersifat memusat bentuk massa bangunan ruang edukasi dan rekreasi ini terdiri dari tiga massa utama. Massa pertama yang bersifat semi-publik berisikan program galeri, masa kedua berisikan menara obeservasi dan di sambungkan dengan konefktivitas komunal area yang ada di tengan di antara kedua masa tersebut, menjadi point of interest dari bangunan ini.
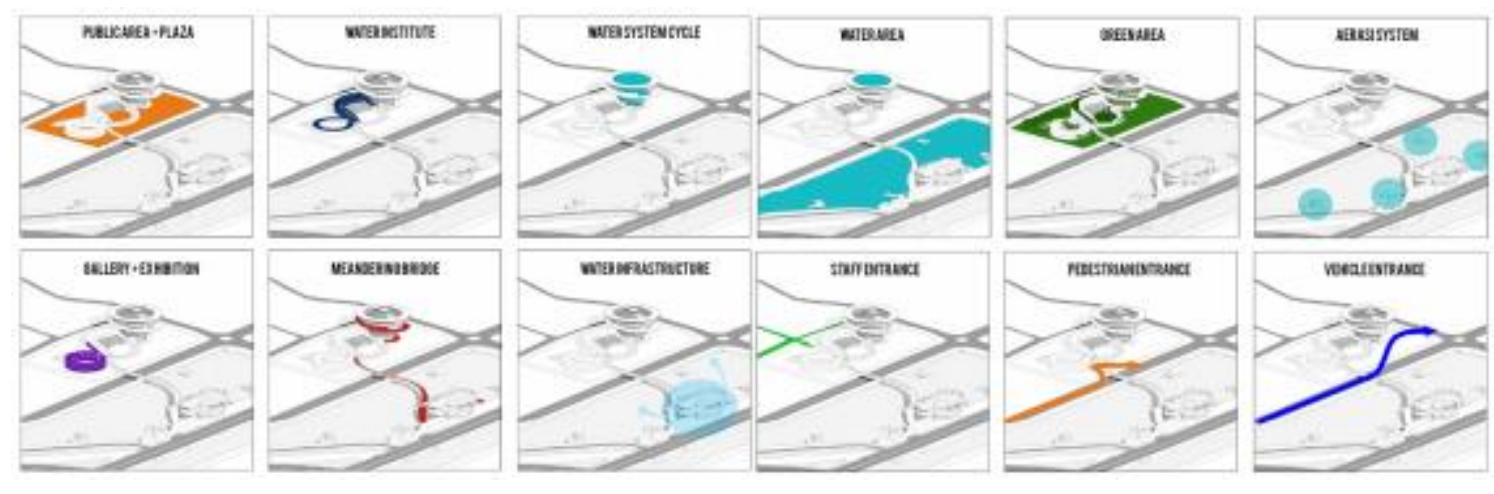

Gambar 5. Masa Bangunan

Sumber: Penulis, 2019 
Ruang edukasi dan rekreasi pengolahan air Jakarta memiliki 9 lantai: lantai bawah di fungsikan sebagai zona publik dan sosial serta komersil sebagai pelengkap. Lantai 2 dan 3 difungsikan galeri edukasi pengolahan air. Pada lantai 3 terdapat jembatan penghubung yang menghubungkan bangunan ke Waduk Setiabudi agar pengunjung mempelajari dan melihat langsung sistem pengolahan air limbah. Lantai 4 hingga 9 merupakanmenara observasi.

Banyak potensi penggunaan publik yang dipertimbangkan dalam perencanaan untuk program ruang edukasi dan rekresi pengolahan air Jakarta ini. Program untuk mengedukasi publik tentang pentingnya air bagi kehidupan kota, Gaya hidup, pengalaman ruang rekreasi baru unutk untuk kegiatan keluarga bersantai, area bermain untuk anak-anak, atraksi untuk wisatawan mancanegara, ruang untuk konferensi khusus dan banyak lagi yang dipertimbangkan. Proyek yang dihasilkan adalah contoh tentang bagaimana proyek awalnya disusun untuk sumber daya air tujuan fungsional dapat berkembang tidak hanya menjadi struktur ikonik tetapi suatu ikon kota yang menarik.

Berikut ini merupakan suasana ruang yang dihasilkan dari desain eksterior dan interior ruang edukasi dan rekreasi pengolahan air Jakarta:

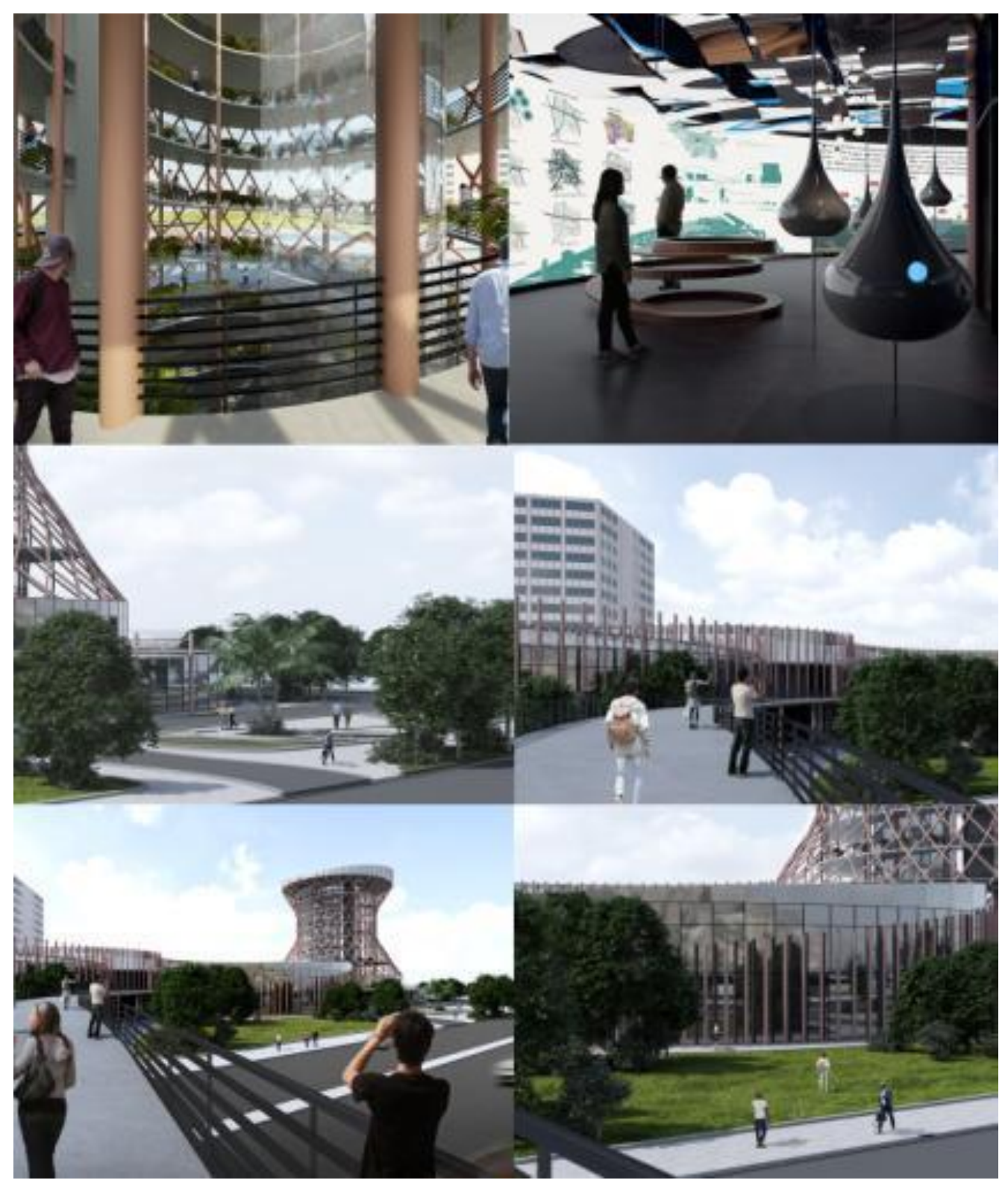

Gambar 6. Suasana Eksterior dan Interior Bangunan

Sumber: Penulis, 2019 
Konsep Ruang Luar dibuat sangat terbuka sehingga pengunjung dapat merasakan elemen alam di dalamnya. Ruang luar bangunan ini terbentuk dari dua elemen yaitu permainan hardscape dan softscape. bentuk bangunan masa yang ikonik akan menjadi suatu bangunan yang contrast di lingkungannya. Pada bagian ruang dalam di desain agar tetap berkonsep terbuka dan menyatu dengan alam dengan upaya memberikan banyak void dan bukaan untuk semakin menekankan pengalaman ruang dimana air dan alam menjadi elemen utamanya. Untuk bagian galeri di desain bersifat tertutup untuk kenyamanan pengunjung dalam menikmati penampilan panel dalam galeri.

Bagian fasad ruang edukasi dan rekreasi pengoahan air Jakarta menggunakan curtain wall yang di kombinasikan dengan bagian solid dengan bangian $1 / 2$ bata + plester di bagian yang privat yang tidak terbuka. Untuk fasad bagian menara / tower mayoritas menggunakan bahan baja (Steel). Pada bagian tower di berikan pola struktur segitiga yang membuat bangunan kontras dan tidak monoton.

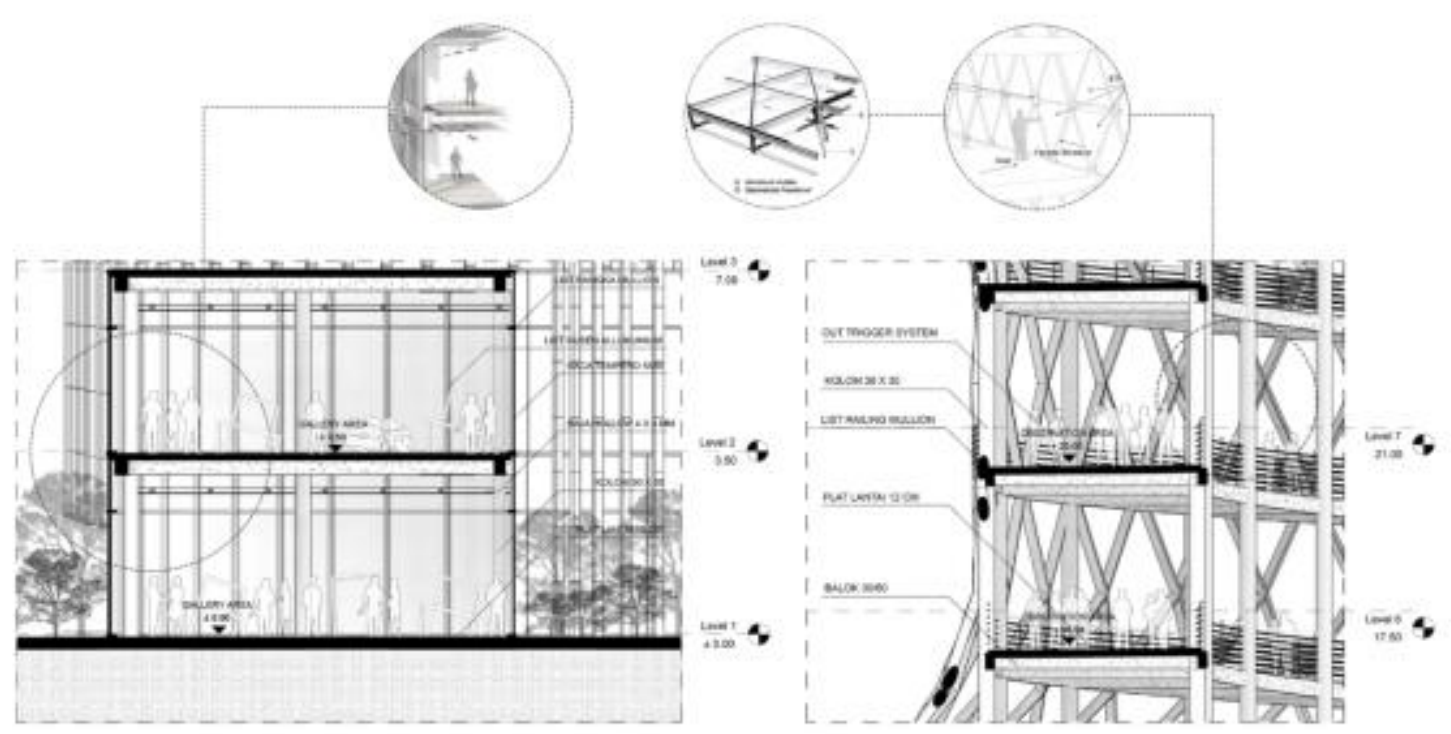

Gambar 7. Analisis Fasad Bangunan

Sumber: Penulis, 2019

Bangunan berpusat kepada Plaza dan Taman juga elemen alam, hal tersebut bukan hanya sebagai bagian eksterior dari bangunan melainkan menjadi area resapan air hujan. Bangunan juga menggunakan sistem hydropower yang mengolah air yang ada di dalam bangunan dengan turbin dan di jadikan sebagai sumber daya bagi bangunan itu sendiri. Adanya banyak bukaan dalam desain juga memaksimalkan keefesianan energi pencahayaan sehingga dapat mengurangi penggunaan listrik.

\section{HYDROELECTRIC POWER}
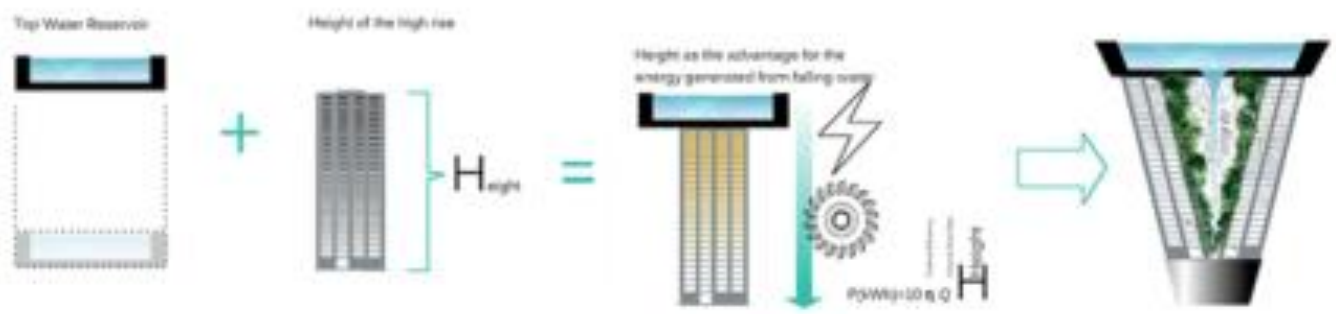

Gambar 8. Diagram Hydopower Sistem

Sumber: Penulis, 2019 
Hydropower sebagai energi terbarukan yang paling efisien. teknologi PLTA yang ada memiliki efisiensi 90\%. itu dapat menanggapi dengan cepat kebutuhan lingkungan saat ini. Siklus air bisa difungsikan sesuai kebutuhan. Dan pada musim kemarau saat tidak hujan Radiasi matahari di Indonesia dan banyak negara terletak di garis khatulistiwa yang intens dan sebagian besar di atas kepala dalam kondisi langit yang cerah. Maka panel surya dapat bekerja.

\section{KESIMPULAN DAN SARAN}

Perkembangan tipologi bangunan pengolahan air limbah telah berkembang menjadi sesuatu yang publik berbeda dari acuan tipologi sebelumnya. Ruang edukasi pengolahan air limbah yang sesuai dengan kebutuhan milenial menciptakan ruang interaksi publik yang baru dan di tambahkan edukasi tentang pengolahan air limbah dengan program yang menarik lainnya.

Disarankan kepada peneliti dan perancang selanjutnya untuk dapat melanjutkan dan menyempurnakan penulisan dengan metode lainnya yang dapat menambahkan data serta studi terkait bangunan pengolahan air limbah Jakarta.

\section{REFERENSI}

Harari Y.H. (2015). Homodeus A Brief History of Tomorrow.

Deviyana. (2016). Jurnal "Taman Rekreasi Edukatif Anak Di Kota Makassar" .Diakses pada Januari 2017.

Setiabudi, W. (2015). Revitalisasi Waduk Setiabudi. Diakses pada Januari 2016, From http://mediaindonesia.com/read/detail/111869-revitalisasi-waduk-setiabudi.

PAL Jaya (2016). Pengolahan Air Limbah Sistem Perppaan Retrieved Januari 2016,From http://www.paljaya.com/jasa-layanan-kami/air-limbah-sistem-perpipaan.

Harian Nasional (2017). DKI Kembangkan waduk setiabudi barat Retrieved 26 Juli 2017, From http://harnas.co/2017/07/06/dki-kembangkan-waduk-setiabudi-barat. 
